\title{
Analysis on English-Chinese Existential Sentence Based on Cognitive Linguistics
}

\author{
Zhong Nan \\ University of Economics and Law, Wuhan, Hubei, 430073 China \\ zhuheng806@163.com
}

Keywords: English existential sentence, Cognitive linguistics, Explanation.

\begin{abstract}
In English learning, English existential sentence is key and difficult point, while applying cognitive linguistics theory to explain English existential sentence can better help people to understand formation and development of English existential sentence. Therefore, this paper uses many kinds of cognitive theories such as reflection-landmark theory, iconicity theory and category theory etc. to explain many problems such as structure, subject-verb agreement, orientation and grammar etc. so as to provide references for people concerning this topic.
\end{abstract}

\section{Introduction}

Existence is the basic category of philosophy, also basic category of human thinking. Indication of language space-time and space concept is just epitome of human thinking. The fundamental cognitive mechanism is also reflected in the space-time of language. In English, existential sentence is indicated by way of There be sentence, while the most usual existential sentence in Chinese is there is or there are. Image background theory derives from psychology; it is one kind of theory based on principle of prominence. People are always tend to divide things into graph and background, of which graph is easily to be sensed, while background can be used as reference to stand out graph. So we can use graph background theory to explore the different thinking models hidden in English-Chinese existential sentence.

\section{Cognitive analysis on existential sentence}

Existence is one kind of special nature of things; it can indicate the existence of things by space positioning. Existential sentence is the language form of mainly indicating space and position relations of things. In English, the general form of existential sentence is There be sentence pattern, in Chinese, the typical form of existential sentence is there is or there are..... Because when people are perceiving space relations, they always regarding one object as graph, it is the direct object to be perceived, while they regard another relevant object as setting, which is reference, to confirm position and direction of things, so English-Chinese existential sentence can start from cognitive perspective and use graph-setting theory to make analysis.

(1) Cognitive analysis of English existential sentence

The typical sentence pattern of English existential sentence is as follows:

(A) There be + NP + Adverbial

Eg: (1) There is a book on the desk.

(2) There are some apples in the basket.

(B) There be + NP + VPing + Adverbial

Eg: (3) There is an old man sitting on the beach.

(4) There are some children playing in the ground.

English existential sentence except to present verb be of static space, there are also some verbs can be used in existence process sentence, for example, there are some verbs indicate exist or arise, such exist, remain, arise etc. This paper only discusses static verb be. From superficial grammar, There be sentence pattern uses there as subject, it is stressed in sentence, but in this structure, there 
means one abstract or uncertain background. But in there be structure, be conjugation accords with NP behind it, this causes the prominent contradiction between there and NP. Writer thinks there means the Adverbial part in the end, it is in the subject position, but it is used as form without any special meanings, while NP is the par firstly appears and has detailed meaning in There be sentence pattern, it should be the part to be featured. So in typical sentence pattern of English existential sentence, NP is graph, which is trajectory, Adverbial part is used as reference, which is landmark. Sometimes, Adverbial may not appear and landmark hides in the background. Under the normal condition, Adverbial indicates prepositional phrase of space relations, while cognitive linguists has early applied trajector-landmark theory to analyze the cognitive meanings of these prepositional phrases. Existential sentence stresses this kind of space relation, so example (1) can be explained by figure 1. Book is trajector and desk is landmark, the whole space is setting. Example (1) stands out trajector, which is book. Similarly, figure 2 analyzes example (2), apples are the obvious trajector, and basket is landmark. 2 example sentences both stand out space relation of trajector and landmark.

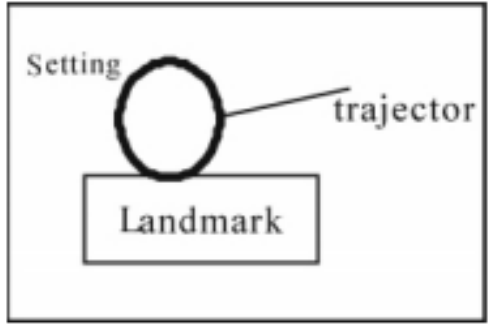

Figure 1

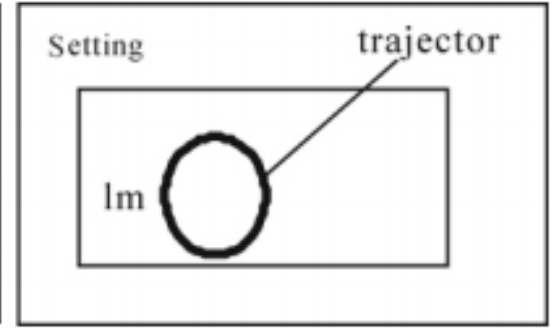

Figure 2

(B) Sentence pattern (B) has additional VPing part, which is the NP action or state in existential sentence. Then it introduces into participant-setting-stage theory to comprehensively analyze example (3) and (4), please refer to figure 3 and figure 4. Of which, reflection man is participant, its state is sitting, while action of children is playing, this is obvious, the whole setting becomes to be one stage, trajector, its action and state, which is the actor and playing on the stage, it is the part should be stressed, while landmark is stage scenery without being stressed.

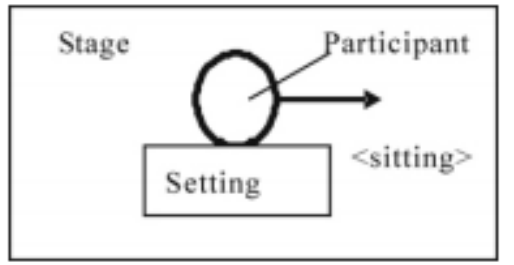

Figure 3

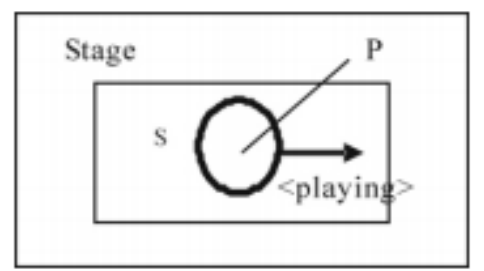

Figure 4

From the above analysis we can see that English prepositional phrase is rich in expression way of language, its space and position relation, it is indicated by prepositional phrase +NP (adverbial), which is existential sentence Therebe $+\mathrm{NP}+$ Adverbial, NP is regarded as graph, which means trajector is in front of Adverbial reference, it means stage appears and stresses the obvious cognition of graph, graph is subject, which becomes to be the cognition subject, things need to be perceived, while reference just has the auxiliary effect of perceiving target position. In the syntactical structure, it uses there as the beginning and appears in front of sentence as know information, form a connecting link between the preceding and the following, so it subsequently introduces target need to be perceived, which conforms to the cognition process from known to unknown, familiar things to unknown things.

2. Cognition analysis of Chinese existential sentence

The typical sentence of Chinese existential sentence is as follows:

(A) Space position+ has + NP

Example: (5) There is a village under the foot of mountain.

(6) 2 old man sit in the living room.

(B) Space position+ has $+\mathrm{NP}+$ in $+\mathrm{VP}$

Example: (7) There is a group of children playing on the playground.

(8) There is bird flying on the roof. 
Chinese existential sentence also has other forms, but this paper mainly surrounds word and sentence with there to develop, because there is the usual measure of Chinese indicates space relation. In these example sentences, position reference become to be the first part in sentence, which means stage scenery becomes to be focus and stressed out. In addition, in Chinese existential sentence, terms indicate position can not be omitted, this also indicates the salience of position as reference. Example (5), mountain foot is stage setting, village is participant, example (7), playground is setting, children is participant, playing is the action sent out by children, example (8) roof is setting, bird is participant, flying is the action sent out by it.

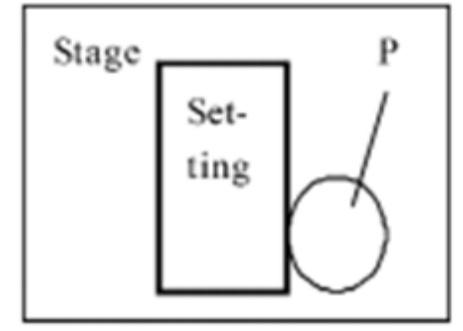

Figure 5

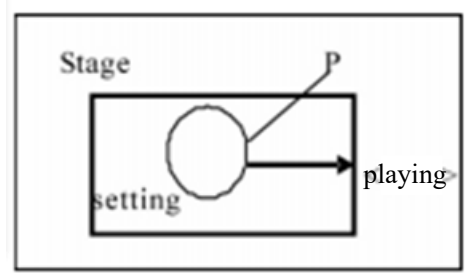

Figure 7

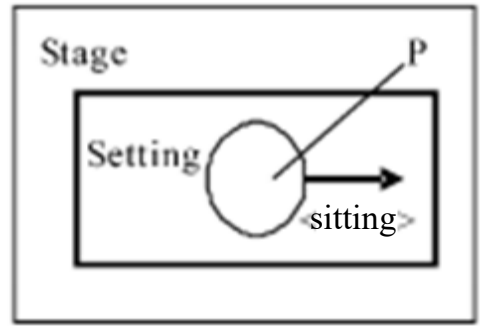

Figure 6

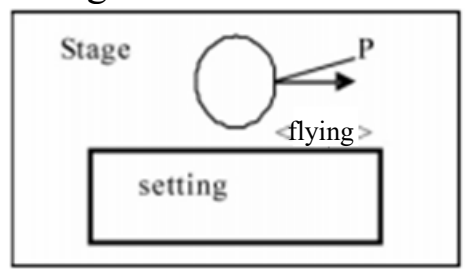

Figure 8

From the form, we can see Chinese has little prepositional phrase but rich position terms, so position relations of Chinese is indicated by NP + position terms, while position terms is just one kind of nouns, so the whole NP + position terms can be used as subject, which stands out reference. There exists word order principle of reference is superior to target in Chinese; it reflects Chinese people tend to have thinking form from the whole to part in perceiving space relation. Chinese has stronger tendency from setting to target in expressing space relations. In the typical Chinese existential sentence, existence place is in the beginning of sentence, existential thing is in the end of sentence, the order of Chinese space position is from large to small, from remote to nearby, which is the cognition order of reference $\rightarrow$ target, which is the order of setting $\rightarrow$ graph. This reflects Chinese people tend to have thinking form from the whole to part in perceiving space relation. This kind of expression uses setting as the beginning of sentence, from one large space concept reduced to small cognition target point, which also indicates the cognition process of human from unknown to known.

Table 1 Substantive characteristic and associative characteristic of graph

\begin{tabular}{|c|c|c|}
\hline $\begin{array}{l}\text { Characterist } \\
\text { ic category }\end{array}$ & Graph & Setting \\
\hline \multirow{3}{*}{$\begin{array}{l}\text { Substantial } \\
\text { characterist } \\
\text { ic }\end{array}$} & $\begin{array}{l}\text { Unknown, space characteristic } \\
\text { need confirmation }\end{array}$ & $\begin{array}{l}\text { Refer to entity, it can remark known characteristic } \\
\text { of graph unpredictability }\end{array}$ \\
\hline & portable & stable \\
\hline & smaller & larger \\
\hline \multirow{6}{*}{$\begin{array}{c}\text { Associative } \\
\text { characterist } \\
\text { ic }\end{array}$} & (geometry) much more simple & (geometry) much more complicated \\
\hline & Enter scenery, predict late & familiar/already predicted \\
\hline & $\begin{array}{l}\text { Arise much more attention, } \\
\text { more correlation }\end{array}$ & arise little attention, less correlation \\
\hline & small immediate consciousness & large immediate consciousness \\
\hline & $\begin{array}{l}\text { Once it is aware it, strong } \\
\text { salience }\end{array}$ & Strong setting \\
\hline & strong dependence & strong independence \\
\hline
\end{tabular}




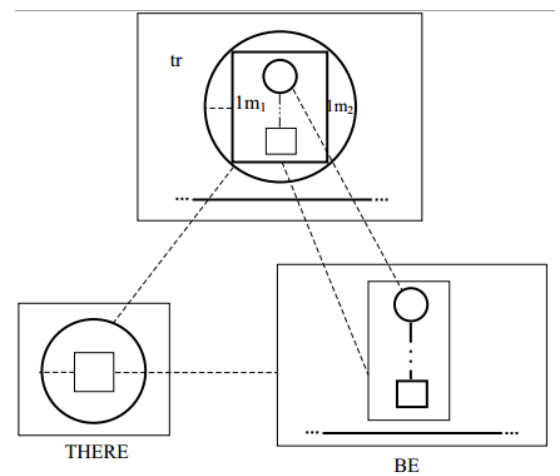

Figure 9 There-be clause structure

As it is indicated by figure 9, one important step in producing there existential sentence is integration of there and be. Semantic entities of bare plural expressions can be divided into object, kind and stage. The so-called object means the detailed individual of object-level, such as one dog, 如 which is called as Fido, then Fido is the individual of object-level. The so-called kind is the thing universally equipped by certain object, it is one kind of concept form, it can be also regarded as one kind of individual, for example, for example, dogs is the DOG individual of kind noun, but its level is kind-level. The so-called stage is the instantiation of individual in certain time and space, in another words, stage is the slices of individual space part, for example, one dog Fido has the action of barking at 9 of morning on $20^{\text {th }}$, June of certain year is the stage of individual Fido, the dog individual with the same kind can have action of barking under the detailed time and space dimension, which means it has its own stage. This semantic entities of object kind, kind individual and kind individual, stage has one kind of relation. It is indicated by the following figure:

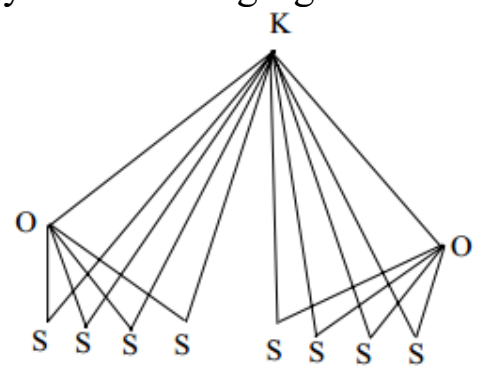

$\mathrm{K}=\mathrm{Kind} \mathrm{O}=\mathrm{Object} \mathrm{S}=$ stage

Figure 10 Semantic subject relation of Carlson

Existential sentence of implementing things in the beginning of sentence constructs one action link, which indicates source-route-target. Here, trajectory implements things, landmark is place, and source-route-target schematic is indicated by the following figure:

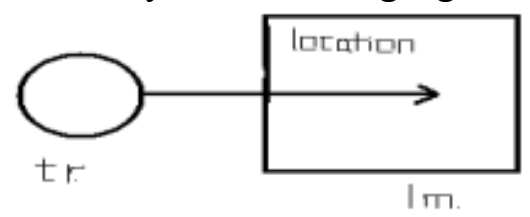

Figure 11 Clause structure of trajector is participant, landmark

From the above graph, we can see that object has three levels, they are stage(S), object(O) and $\operatorname{kind}(\mathrm{K})$ from the bottom to top, 2 different kinds of individuals both have their stages(example under certain space condition).

\section{Conclusion}

Cognitive linguistics stresses effect and restriction of human culture on language structure, each nation has unique characteristic in cognition process. As for cognition system of human, 2 different objects in space have unbalanced significance. In the cognition process of space relation by human, they usually regard one thing as the direct target to be perceived, which is graph, while regard things 
with setting relation as reference, which is setting, it uses this as cognition mechanism of experiencing space direction and position. Because people have different salience in perceiving things, existential sentence structure in Chinese and English of expressing space and position relation also has difference. Therefore, different language structures also reflect different cognition forms. English has the cognition process from individual to the whole, while Chinese has cognition process from the whole to part. The similarity lies in that Chinese and English both indicate the cognition process of people from familiar to unknown, from known to unknown.

\section{References}

[1] Cui Shan, Qiu Zhijing. Application of Concept Grammar Metaphor in Business English Advertisement [J]. Journal of Mudanjiang Normal University (edition of social sciences), 2014, 05:103-104.

[2] Du Xiaochuan. Research on Metaphor in English Advertisement [J]. Journal of Jilin Radio and Television University, 2013, 07:70-71.

[3] Hu Weizhi. Application and Research on Metaphor in English Advertisement under Perspective of Co-relation Theory [J]. Journal of Inner Mongol Normal University (education science edition), 2016, 12:142-144.

[4] Zhao Na. Analysis on Concept Metaphor in English Advertisement [J]. Science Education Article Collects (published in the first ten-day period of a month), 2012, 02:134+146.

[5] Wang Suping. Discussion on Different Function of Metaphor in English Advertisement [J]. Pingxiang College Journal, 2016, 04:93-95. 